\title{
Phytochemical Constituents Identified from the Aerial Parts of Lespedeza cuneata and Their Effects on Lipid Metabolism during Adipocyte Maturation
}

\author{
Heesun Kang ${ }^{1,+}$, Min Jeong Yoo ${ }^{1,+}$, Sang Ah Yi ${ }^{1}{ }^{1}$, Tae Wan Kim ${ }^{1}$, Ji Won Ha ${ }^{1}$, Myung Woo Na ${ }^{1}$, Kun Hee Park ${ }^{2}$, \\ Seon-Hee Kim ${ }^{3}$, Jeung-Whan Han ${ }^{1}$, Tae Su Jang ${ }^{4}$ and Ki Hyun Kim ${ }^{1, * \mathbb{D}}$ \\ 1 School of Pharmacy, Sungkyunkwan University, Suwon 16419, Korea; hskang428@g.skku.edu (H.K.); \\ kch970513@naver.com (M.J.Y.); angelna1023@hanmail.net (S.A.Y.); asde8282@naver.com (T.W.K.); \\ ellenha2@gmail.com (J.W.H.); myeong500@naver.com (M.W.N.); jhhan551@skku.edu (J.-W.H.) \\ 2 Department of Food Science and Biotechnology, Sungkyunkwan University, Suwon 16419, Korea; \\ soske@skku.edu \\ 3 Sungkyun Biotech Co., Ltd., Suwon 16419, Korea; seonhee31@gmail.com \\ 4 College of Medicine, Dankook University, Cheonan 31116, Korea; jangts@dankook.ac.kr \\ * Correspondence: khkim83@skku.edu; Tel.: +82-31-290-7700 \\ + These authors contributed equally to this study.
}

\section{check for} updates

Citation: Kang, H.; Yoo, M.J.; Yi, S.A.; Kim, T.W.; Ha, J.W.; Na, M.W.; Park,

K.H.; Kim, S.-H.; Han, J.-W.; Jang, T.S.;

et al. Phytochemical Constituents

Identified from the Aerial Parts of

Lespedeza cuneata and Their Effects on

Lipid Metabolism during Adipocyte

Maturation. Separations 2021, 8, 203.

https://doi.org/10.3390/

separations 8110203

Academic Editor: Eduardo Sommella

Received: 13 October 2021

Accepted: 1 November 2021

Published: 3 November 2021

Publisher's Note: MDPI stays neutral with regard to jurisdictional claims in published maps and institutional affiliations.

Copyright: (c) 2021 by the authors. Licensee MDPI, Basel, Switzerland. This article is an open access article distributed under the terms and conditions of the Creative Commons Attribution (CC BY) license (https:/ / creativecommons.org/licenses/by/ $4.0 /)$.

\begin{abstract}
Lespedeza cuneata, belonging to Fabaceae, is well-known as Chinese bushclover, and it has been used in traditional folk medicines for the treatment of disorders, such as diabetes, hematuria, and insomnia. As part of continuing research projects to discover interesting natural compounds with biological activities from Korean medicinal plants, the phytochemical investigation of L. cuneata resulted in the isolation of five chemical constituents: $\alpha$-tocopherol (1), 7a-methoxy- $\alpha$-tocopherol (2), 13(R)-hydroxy-octadeca-(9Z,11E,15Z)-trien-oic acid (3), $\alpha$-dimorphecolic acid (4), and lupeol (5). The structural determination of the isolated compounds was elucidated from data gathered through nuclear magnetic resonance (NMR) spectroscopy and liquid chromatography-mass spectrometry (LC/MS). Until now, this study is the first to report these five compounds from the plant L. cuneata. Moreover, these isolated compounds (1-5) were evaluated for their anti-adipogenesis effects and their role in lipid metabolism during adipocyte maturation. As a result, the upregulation of mRNA expression levels of Fabp 4 from 3T3-L1 pre-adipocytes treated with compounds 3 and 4 demonstrated that these compounds efficiently induced adipocyte differentiation. Furthermore, compounds 3 and 4 were found to regulate lipid metabolism by the induction of lipolytic and of lipogenic gene expressions. Therefore, experimental data from these findings supported that the compounds 3 and 4 induce the adipogenesis of 3T3-L1 pre-adipocytes and regulate lipid metabolism.
\end{abstract}

Keywords: Lespedeza cuneata; Fabaceae; structural elucidation; 3T3-L1 pre-adipocytes; adipogenesis

\section{Introduction}

Obesity is known to be characterized by the expansion of adipose tissue, which induces various metabolic complications including type 2 diabetes and hypertension [1]. Adipose tissue expansion is directly caused by two mechanisms: (1) disruption of the process of precursor cells' differentiation into mature adipocytes (adipogenesis) and (2) excessive lipid accumulation in adipocytes (lipogenesis) [2]. Thus, targeting adipogenesis and lipid metabolism can be a necessary requirement to manage the health conditions of obesity.

Lespedeza cuneata, belonging to the family Fabaceae, is well-known as a Chinese bushclover and a perennial legume that thrives during the warm season. It is generally distributed throughout Korea, China, and India [3]. As an important Korean medicinal plant, L. cuneata has been applied in traditional folk medicines to treat liver, kidney, and lung disorders and other diseases, such as diabetes, hematuria, and insomnia [4,5]. Previous studies on this plant for its pharmacological properties have reported that the 
extracts of L. cuneata have antidiabetic and hepatoprotective activities [3,4,6,7]. Some studies revealed that the extracts of L. cuneata showed pharmacological properties such as protection against testicular and ovarian diseases [8,9]. In addition, chemical investigations on L. cuneata demonstrated various chemical constituents with a large variety of bioactivities [10]. Among the identified constituents, flavonoids and lignans were identified as the main classes of constituents in L. cuneata. The flavonoids of L. cuneata reportedly show the inhibitory effects of nitric oxide (NO) [7,11], while the lignans exhibit anti-ulcerative colitis and hepatoprotective effects [6,12]. Overall, the previous database [6-12] on this plant suggest the potential of L. cuneata for treating diseases through diverse bioactive compounds.

Due to our interest in discovering novel natural products with interesting structural features and/or biological activities [13-17], a phytochemical study of the $\mathrm{MeOH}$ extract from the aerial parts of L. cuneata was conducted. Based from the previous chemical investigation of L. cuneata, we discovered an active lignan $\left[(-)-9^{\prime}-O-(\alpha-\mathrm{L}\right.$-rhamnopyranosyl) lyoniresinol] using the bioassay-guided fractionation technique. We found that the lignan significantly reduced proliferation of human ovarian carcinoma cells (A2780) by inducing apoptosis [17]. Also in another previous study, we isolated five lignan glycosides including two new lignan derivatives, along with nine flavonoid glycosides [18,19], the structures of which were characterized successfully. Several of these compounds exhibited cytotoxicity against human breast cancer cell lines (MCF-7, HCC70, MDA-MB-231, and Bt549) [18]. Specifically, we found that aviculin, a bioactive lignan, showed inhibitory effects of human tumor cell growth. This is explained by the apoptotic cell death of the intrinsic apoptosis pathway, increasing the expression of executioner caspase-7, initiator caspase-9, and poly (ADP-ribose) polymerase. In this study, phytochemical analysis of the aerial parts of L. cuneata led to the identification of bioactive constituents: two tocopherol derivatives (1 and 2), two fatty acids (3 and 4 ), and a triterpenoid (5). The structures of the compounds (1-5) isolated were established by liquid chromatography/mass spectrometry (LC/MS) analysis combined with the application of nuclear magnetic resonance (NMR) spectroscopic data analysis and physical data, and by comparison with previously reported NMR values. Herein, we report the structural elucidation of compounds 1-5 as well as the biological evaluation of their role in adipogenesis and lipid metabolism in adipocytes.

\section{Materials and Methods}

\subsection{Plant Material}

L. cuneata materials were gathered in October 2016 from Mt. Bangtae, Inje, and Kangwon provinces located in the Republic of Korea. The plant material was verified by Prof. K. H. Kim, one of the authors of this paper. A voucher specimen, namely YKM2016, was stored at the herbarium of the School of Pharmacy, which is affiliated with Sungkyunkwan University, Suwon, Korea.

\subsection{Extraction and Isolation}

The desiccated aerial portions of the plant L. cuneata $(3.8 \mathrm{~kg})$ were extracted three times with $4.0 \mathrm{~L}$ of $80 \% \mathrm{MeOH}$ (purity $99.5 \%$ ) for $72 \mathrm{~h}$ at room temperature and then followed by sediment filtration. The $\mathrm{MeOH}$ extract $(390.5 \mathrm{~g}$ ) was obtained by rotary evaporator after removing the solvent. The extract was suspended in the distilled $\mathrm{H}_{2} \mathrm{O}(2 \mathrm{~L})$ and then solvent-partitioned three times using four organic solvents, $n$-hexane, $\mathrm{CH}_{2} \mathrm{Cl}_{2}$, EtOAc, and $n-\mathrm{BuOH}$ (1.8 L for each solvent), respectively. The resultant solvent partitioned fractions were the $n$-hexane- $(19.5 \mathrm{~g}), \mathrm{CH}_{2} \mathrm{Cl}_{2}-(0.6 \mathrm{~g})$, EtOAc- $(11.9 \mathrm{~g})$, and $n$-BuOH-soluble fractions $(65.1 \mathrm{~g})$, respectively. The $n$-hexane-soluble fraction $(18.5 \mathrm{~g})$ was separated by silica gel open-column chromatography with the gradient solvent system of hexane-EtOAc (40:1-30:1-20:1-10:1-5:1-2:1-1:1-0:1) to afford twelve fractions (A-L) based on the TLC analysis. Fraction D (390.8 mg) was separated by RP-C 18 open-column chromatography with $50 \%$ $\mathrm{MeOH}(800 \mathrm{~mL})$ yielding fourteen sub-fractions (D1-D14) by TLC analysis. Sub-fraction D8 (28.5 mg) was purified using semi-preparative HPLC system with a Phenomenex Luna 
phenyl-hexyl column (the solvent condition of $75 \% \mathrm{MeCN}$ at flow rate of $2 \mathrm{~mL} / \mathrm{min}$ ) to give compounds 1 ( $\left.9.0 \mathrm{mg}, t_{\mathrm{R}}=28.2 \mathrm{~min}\right)$ and $2\left(4.6 \mathrm{mg}, t_{\mathrm{R}}=40.7 \mathrm{~min}\right)$. In addition, based on the TLC analysis, the fraction K (595.9 mg) yielded nine sub-fractions (K1-K9), which were obtained using $\mathrm{RP}^{-\mathrm{C}_{18}}$ open-column chromatography with the gradient solvent system of $\mathrm{MeOH}-\mathrm{H}_{2} \mathrm{O}(30-100 \% \mathrm{MeOH})$. Compounds $3\left(4.8 \mathrm{mg}, t_{\mathrm{R}}=35.1 \mathrm{~min}\right)$ and $4(6.8 \mathrm{mg}$, $\left.t_{\mathrm{R}}=44.2 \mathrm{~min}\right)$ were purified from sub-fraction $\mathrm{K} 4(134.9 \mathrm{mg})$ by semi-preparative HPLC system using the Phenomenex Luna phenyl-hexyl column (the solvent condition of $70 \%$ $\mathrm{MeOH}$ at flow rate of $2 \mathrm{~mL} / \mathrm{min})$. Finally, Fraction E (1.4 g) was obtained by separation through column chromatography of Sephadex LH-20 eluted with $\mathrm{CH}_{2} \mathrm{Cl}_{2}-\mathrm{MeOH}$ (1:2) to yield fifteen sub-fractions (E1-E15) based on TLC analysis. Compound 5 (128.0 mg, $\left.t_{\mathrm{R}}=42.5 \mathrm{~min}\right)$ was separated from sub-fractions E9 $(613.7 \mathrm{mg})$ using semi-preparative HPLC system (the solvent condition of $78 \% \mathrm{MeCN}$ at flow rate of $2.0 \mathrm{~mL} / \mathrm{min}$ ) using the Phenomenex Luna phenyl-hexyl column. NMR and physical data of the isolated compounds are included in Supplementary Materials.

\subsection{Cell Culture and Differentiation}

3T3-L1 pre-adipocytes, obtained from the American Type Culture Collection (ATCC ${ }^{\circledR}$ CL-173 ${ }^{\mathrm{TM}}$ ), were grown using Dulbecco Modified Eagle Medium (DMEM) supplemented with $1 \%$ penicillin/streptomycin $(\mathrm{P} / \mathrm{S})$ and $10 \%$ bovine calf serum in a $5 \% \mathrm{CO}_{2}$ humidified incubator. For adipogenic differentiation, 3T3-L1 cells were incubated for two days in MDI induction medium. The MDI induction medium was composed of DMEM with $10 \%$ fetal bovine serum (FBS), 1\% P/S, $0.5 \mathrm{mM}$ 3-isobuyl-1-methylxanthine (IBMX), $1 \mu \mathrm{M}$ dexamethasone, and $10 \mu \mathrm{g} / \mathrm{mL}$ insulin. Then, the medium was switched to DMEM containing $10 \% \mathrm{FBS}, 1 \% \mathrm{P} / \mathrm{S}$, and $10 \mu \mathrm{g} / \mathrm{mL}$ insulin on alternating days until day 10 . To test for the significance of compounds 1-5, 3T3-L1 cells were treated with the following compounds to evaluate their effects on adipogenesis. As a negative control, the same volume of DMSO was used. On day 10, we used Oil Red-O staining to visualize the lipid droplets and harvested the cells for RT-qPCR.

\subsection{Oil Red O Staining}

Oil Red O staining was performed to visually detect the lipid droplets in differentiated adipocytes. Oil Red O powder (300 mg) was dissolved in $100 \mathrm{~mL}$ of $99 \%$ isopropyl alcohol to prepare the Oil Red O stock solution. Then, $30 \mathrm{~mL}$ of the prepared stock solution was diluted with $20 \mathrm{~mL}$ of distilled water to prepare the Oil Red $\mathrm{O}$ working solution just before use. After adipogenesis (day 10), the mature adipocytes were fixed with 10\% formaldehyde for $15 \mathrm{~min}$ and then washed with $60 \%$ isopropyl alcohol. The fixed cells were stained with the Oil Red $\mathrm{O}$ working solution for $1 \mathrm{~h}$ at room temperature, and then the cells were washed with phosphate-buffered saline (PBS). The stained lipids were visualized using a Leica DMi1 inverted microscope (Leica Microsystems Korea, Seoul, Korea).

\subsection{Western Blot}

For protein extraction, adipocytes were lysed in Pro-Prep (Intron Biotechnology, Seongnam, Korea; \#17081) and extracted proteins were subjected to SDS-polyacrylamide gel electrophoresis (SDS-PAGE). Separated proteins were transferred to polyvinylidene difluoride (PVDF) membranes using semi-dry transfer (Bio-Rad, Hercules, CA, USA). The membranes were incubated with the indicated primary antibodies overnight at $4{ }^{\circ} \mathrm{C}$. AntiA-FABP (Santa Cruz Biotechnology, Dallas, TX, USA; SC-271529) and anti-actin (Millipore, Burlington, MA, USA; mab1501) were used as primary antibodies. Then, the membranes were incubated with horseradish peroxidase-conjugated secondary antibodies (Abcam, Cambridge, UK) for $1 \mathrm{~h}$. The detected signals of immunoblot band were reacted with chemiluminescence reagents (Abclon, Guro, Korea) and were exposed with an ImageJ software (ImageJ bundled with 64-bit Java 1.8.0_172) and normalized by the signal of actin. 


\subsection{Reverse Transcription and Quantitative Real-Time PCR (RT-qPCR)}

The Easy-Blue reagent (Intron Biotechnology, Seongnam, Korea) was utilized to extract total RNA from the adipocytes. For reverse transcription (RT), $1 \mu \mathrm{g}$ of extracted total RNA with Maxim RT-PreMix Kit (Intron Biotechnology, Seongnam, Korea) was reverse transcribed into cDNA using the ImProm-II Reverse Transcription System (Promega, Fitchburg, WI, USA). The cDNA was mixed with KAPATM SYBR FAST qPCR (Kapa Biosystems, Wilmington, MA, USA), and the primers used for quantitative real-time PCR (qPCR) are indicated below. The qPCR reaction was detected using a CFX96TM or Chromo4 real-time PCR detector (Bio-Rad, Hercules, CA, USA). Relative mRNA expression was quantified and normalized to $\beta$-actin mRNA expression for each reaction. The sequences of qPCR primers used in the current study are shown in Table 1.

Table 1. Sequences of primers used for RT-qPCR.

\begin{tabular}{crc}
\hline Gene & Forward & Reverse \\
\hline$\beta$-Actin & $5^{\prime}$-ACGGCCAGGTCATCACTATTG-3' & 5'-TGGATGCCACAGGATTCCA-3 $^{\prime}$ \\
Fabp 4 & $5^{\prime}$-AAGGTGAAGAGCATCATAACCCT-3' & $5^{\prime}$-TCACGCCTTTCATAACACATTCC-3' \\
ATGL & $5^{\prime}$-TTCACCATCCGCTTGTTGGAG-3' & $5^{\prime}$-AGATGGTCACCCAATTTCCTC-3 ${ }^{\prime}$ \\
SREBP1 & $5^{\prime}$-AACGTCACTTCCAGCTAGAC-3' & $5^{\prime}$-CCACTAAGGTGCCTACAGAGC-3' $^{\prime}$ \\
\hline
\end{tabular}

\subsection{Statistical Analysis}

The averages and error bars are expressed as standard error of the mean (SEM) for $n=3$ samples. The statistical significance was analyzed by using two-tailed Student's $t$-test using Excel and evaluated through a $p$-values. ${ }^{*} p<0.05,{ }^{* *} p<0.01$, and ${ }^{* * *} p<0.001$ vs. the control group.

\section{Results and Discussion}

\subsection{Isolation and Identification of the Compounds}

The aerial portions of L. cuneata were extracted with $80 \% \mathrm{MeOH}$ at room temperature for three days. The obtained $\mathrm{MeOH}$ extract was partitioned with four organic solvents in the corresponding order: hexane, dichloromethane $\left(\mathrm{CH}_{2} \mathrm{Cl}_{2}\right)$, ethyl acetate (EtOAc), and $n$-butanol $(n-\mathrm{BuOH})$ to obtain solvent fraction of each sample (Figure 1). The hexanesoluble fraction was then further analyzed using repeated column chromatography and HPLC purification along with LC/MS analysis utilized with a house-built UV library. Semipreparative HPLC separation yielded five compounds (Figure 1): $\alpha$-tocoperol (1,9.0 mg), 7a-methoxy- $\alpha$-tocopherol $(2,4.6 \mathrm{mg}), 13(R)$-hydroxy-octadeca-(9Z,11E,15Z)-trien-oic acid $(3,4.8 \mathrm{mg}), \alpha$-dimorphecolic acid $(4,6.8 \mathrm{mg})$, and lupeol $(5,128.0 \mathrm{mg})$. The structures for compounds 1-5 (Figure 2) were determined according to spectroscopic methods, including ${ }^{1} \mathrm{H}$ and ${ }^{13} \mathrm{C}$ NMR spectra (Figures S1 and S2 for 1, Figure S4 for 2, Figure S6 for 3, Figure S8 for 4, Figures S10 and S11 for 5) using comparison of their spectroscopic data, as previously reported in the literature [20-23] and LC/MS analysis (Figure S3 for 1, Figure S5 for 2, Figure S7 for 3, Figure S9 for 4, Figure S12 for 5). 


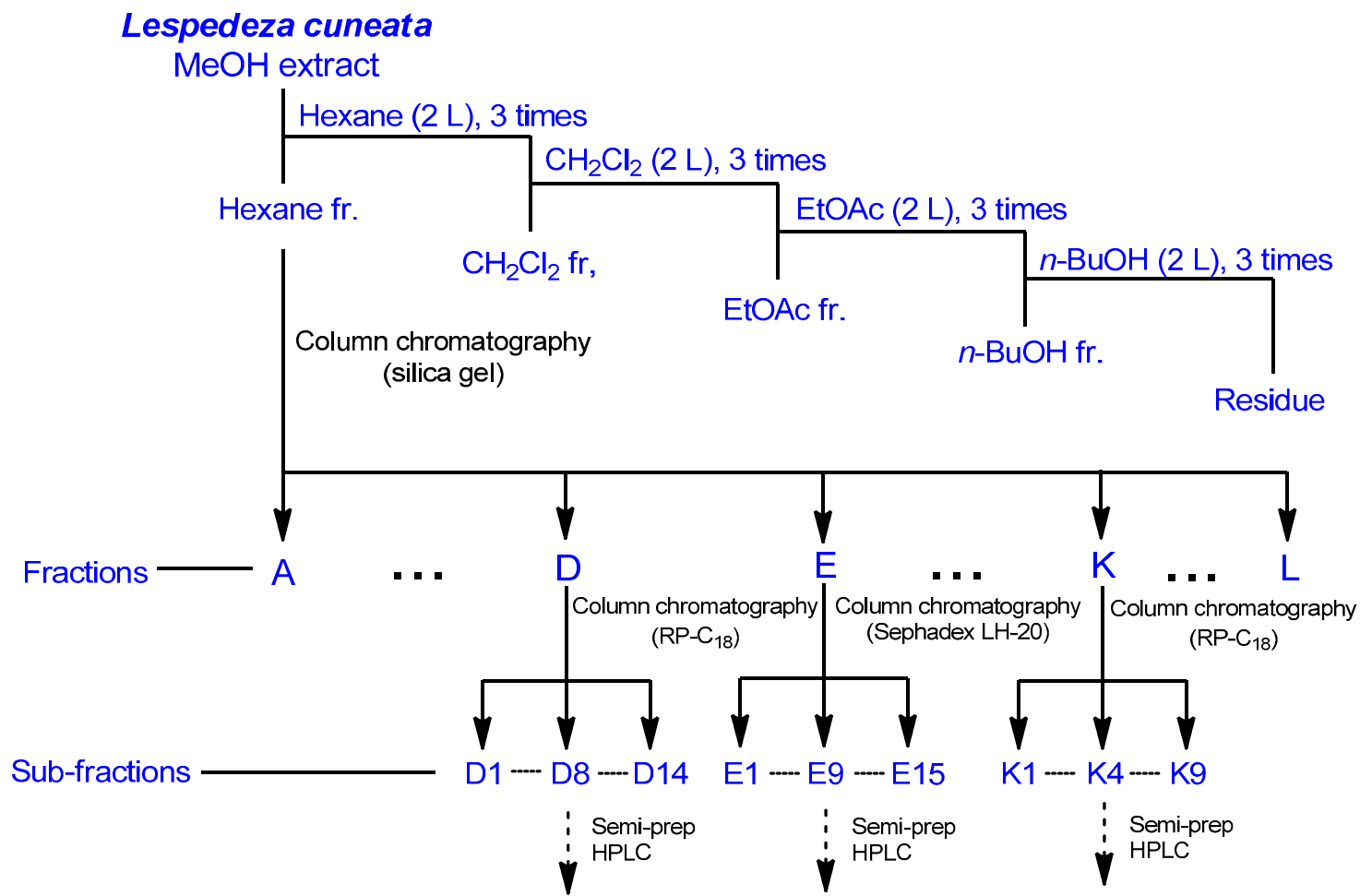

Pure compounds

(5)

(3)

(2)

Figure 1. Separation scheme of compounds 1-5.

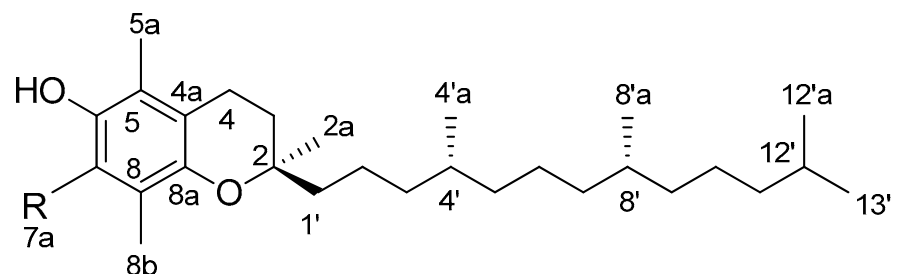

$$
\begin{array}{ll}
1 \mathrm{R}=\mathrm{CH}_{3} \\
2 \mathrm{R}=\mathrm{CH}_{2} \mathrm{OCH}_{3}
\end{array}
$$<smiles>CC/C=C/C[C@@H](O)/C=C/C=C/CCCCCCCC(=O)O</smiles>

3<smiles>CCCCCC=CC=C[C@@H](O)CCCCCCCC(=O)O</smiles>

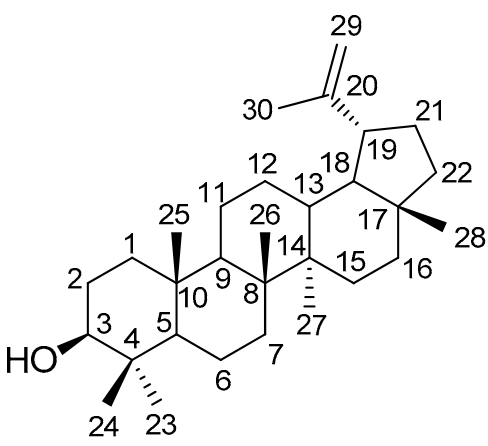

5

4

Figure 2. Chemical structures of compounds (1-5) separated from L. cuneata.

\subsection{Evaluation of Effects of the Compounds on Lipid Metabolism}

Obesity is known to be the excessive accumulation of body fat in adipose tissues, leading to the enlargement and increased number of adipocytes [1]. The storage of fat in adipose tissue is accumulated by the processes of de novo adipocyte generation and lipid drop formation within adipocytes. The excessive lipid accumulation results in addition of 
triglycerides (TG) to existing lipid droplets, thereby induces lipid droplets enlargement [24]. However, in the case of increased energy demand, the stored fat is utilized by lipolysis to generate energy. During the lipolysis, lipids stored in adipocytes are hydrolyzed by lipases such as ATGL and HSL [24]. The modulation of TG storage (lipogenesis) and TG lysis (lipolysis) is critical for the normal regulation of energy balance [25,26]. Therefore, approaches to discover active compounds that regulate adipogenesis and lipogenesis have attracted attention for obesity management as well as the management of other related metabolic diseases, which led us to test the identified compounds 1-5 for their role in regulating lipid metabolism during adipogenesis.

To examine the effects of compounds 1-5 on adipogenesis, 3T3-L1 pre-adipocytes were evaluated with these compounds at a concentration of $10 \mu \mathrm{M}$ during the entire process of adipogenesis for ten days (Figure 3A). These cells were given ten days to differentiate, and then lipid droplets within the mature adipocytes were stained using the Oil Red O staining solution [27]. Oil Red O staining data showed that adipogenesis and lipid accumulation within adipocytes increased when incubated with compounds 2-4, whereas the effects of compound $\mathbf{1}$ and $\mathbf{5}$ on the number and size of adipocytes were hard to evaluate (Figure 3B). Thus, we performed Western blot and RT-qPCR to assess the expression of adipogenic marker. Protein level of a representative adipogenic marker, A-FABP, slightly increased upon treatment with compounds $\mathbf{1}$ and 2, but decreased by compound $\mathbf{5}$ (Figure 3C). The mRNA expression of the mature adipocyte marker gene (Fabp4) was increased upon exposure to $10 \mu \mathrm{M}$ of compounds $2-\mathbf{4}$ during adipocyte maturation, which indicated that these active compounds can facilitate triacylglycerol storage [28]. Therefore, we assessed the capacity of compounds 1-5 for regulating lipid metabolism through the expression of the lipolytic gene, $A T G L$, and lipogenic gene, SREBP1. Consequently, the mRNA expression of the lipolytic gene $A T G L$ was found to be upregulated after exposure to $10 \mu \mathrm{M}$ of compounds $\mathbf{3}$ and $\mathbf{4}$, whereas exposure to compound $\mathbf{5}$ downregulated mRNA expression of ATGL during adipocyte maturation (Figure 3D). In addition, the expression of the lipogenic gene SREBP1 was upregulated after treatment of all compounds, except for compound 1 (Figure 3D). These results further support that compounds 3 and 4 induce adipogenesis of 3T3-L1 pre-adipocytes and serve a role in the regulation of lipid metabolism.

Several researchers have demonstrated the role of fatty acid analogues in regulating lipid accumulation [29,30]. Previous studies reported that lipid accumulation in adipocytes occurred in response to unsaturated fatty acids, such as linoleic acid and oleic acid [29,30]. This report was consistent with the results derived from our previous work [26], where pantheric acids A-C, identified from Amanita pantherina, one of the poisonous mushrooms in Korea, led to an expansion of lipid droplets from 3T3-L1 adipocytes and promoted lipid accumulation through lipogenesis and inhibition of lipolysis [26]. 


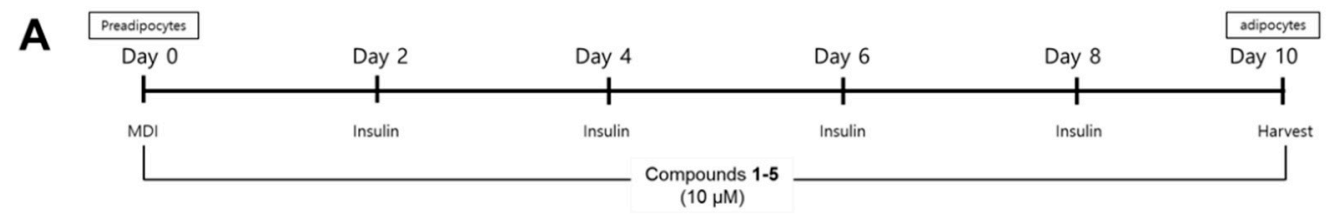

B

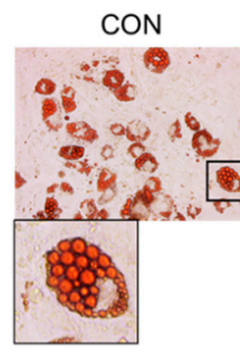

3

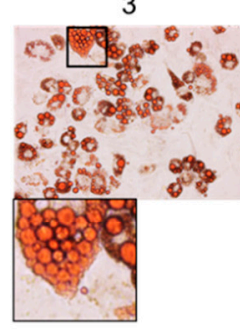

D

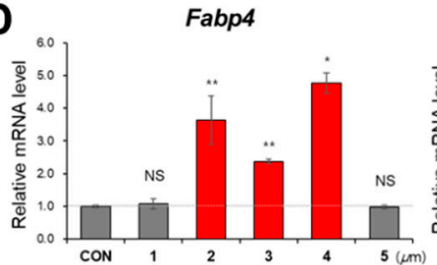

1

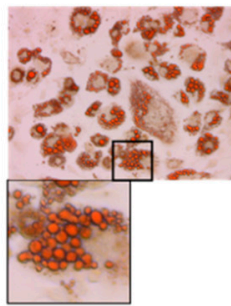

4

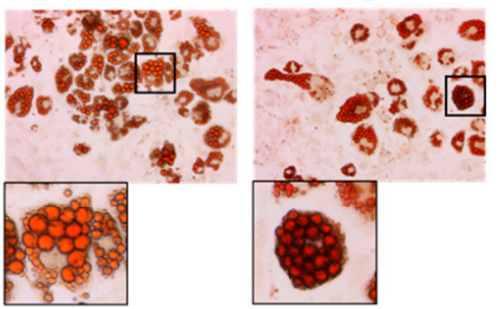

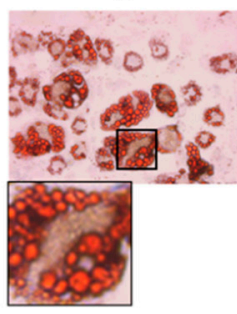

ATGL
C
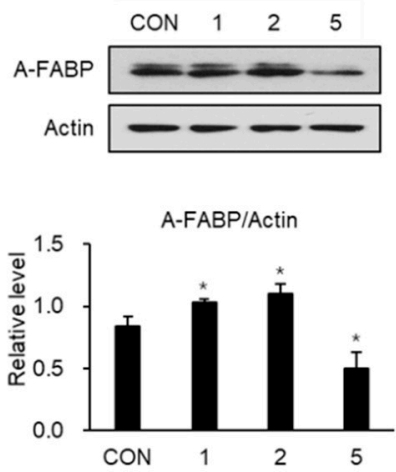
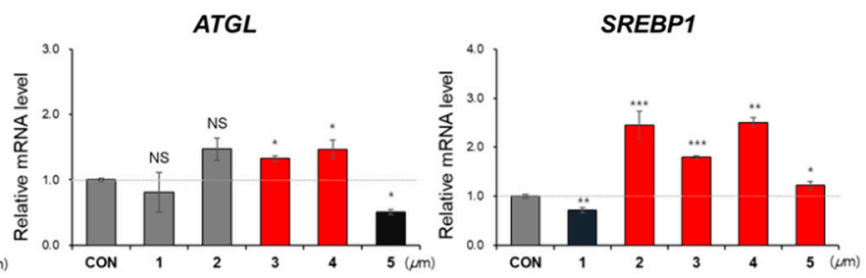

Figure 3. Evaluation of effects of compounds 1-5 on adipogenesis. (A) Schematic representation of 3T3-L1 differentiation into adipocytes. (B) Oil Red O staining of 3T3-L1 adipocytes incubated with $10 \mu \mathrm{M}$ of compounds 1-5 during adipogenesis. (C) Immunoblot analysis of 3T3-L1 adipocytes incubated with $10 \mu \mathrm{M}$ of compounds 1, 2, and 5 during adipogenesis. (D) Relative mRNA expression of Fabp4, ATGL, and SREBP1 in 3T3-L1 adipocytes incubated with $10 \mu \mathrm{M}$ of compounds 1-5 during adipogenesis. The data represent the mean \pm SEM for $n=3 .{ }^{*} p<0.05,{ }^{* *} p<0.01,{ }^{* * *} p<0.001$.

\section{Conclusions}

In conclusion, compounds $\mathbf{1 - 5}$, which were isolated from L. cuneata, were determined to be two tocopherol derivatives, $\alpha$-tocoperol (1), 7a-methoxy- $\alpha$-tocopherol (2), two fatty acids, 13(R)-hydroxy-octadeca-(9Z,11E,15Z)-trien-oic acid (3), $\alpha$-dimorphecolic acid (4), and a triterpenoid, lupeol (5). Through thorough investigation of past studies until now, we report that all the isolated compounds were found for the first time from L. cuneata. Evaluation of effects of compounds $\mathbf{1 - 5}$ was conducted for their anti-adipogenesis activity and lipid metabolism throughout different stages of adipocyte differentiation. As shown in the results, compounds 3 and $\mathbf{4}$ demonstrated the upregulation of the mRNA expression levels of Fabp4, a mature adipocyte marker gene, supporting that these compounds efficiently induced adipocyte differentiation from 3T3-L1 pre-adipocytes. Furthermore, we have discovered that compounds 3 and 4 regulated lipid metabolism by promoting the expression of lipolytic and lipogenic genes, ATGL and SREBP1, respectively. These findings herein provide evidence that the two fatty acid derivatives isolated from L. cuneata ( 3 and 4) induce adipogenesis of 3T3-L1 pre-adipocytes and regulate lipid metabolism.

Supplementary Materials: The following are available online at https: / www.mdpi.com/article / 10.3390/separations8110203/s1, Figure S1: ${ }^{1} \mathrm{H}-\mathrm{NMR}$ spectrum of compound $\mathbf{1}$ (in $\mathrm{CDCl}_{3}$ ), Figure S2:

${ }^{13} \mathrm{C}-\mathrm{NMR}$ spectrum of compound $\mathbf{1}$ (in $\mathrm{CDCl}_{3}$ ), Figure S3: LC/MS data (detection wavelength was 
set as $254 \mathrm{~nm}$ ) of compound 1, Figure S4: ${ }^{1} \mathrm{H}-\mathrm{NMR}$ spectrum of compound 2 (in $\mathrm{CD}_{3} \mathrm{OD}$ ), Figure S5: LC/MS data (detection wavelength was set as $315 \mathrm{~nm}$ ) of compound 2, Figure S6: ${ }^{1} \mathrm{H}-\mathrm{NMR}$ spectrum of compound 3 (in $\mathrm{CD}_{3} \mathrm{OD}$ ), Figure S7: LC/MS data (detection wavelength was set as $315 \mathrm{~nm}$ ) of compound 3, Figure S8: ${ }^{1} \mathrm{H}-\mathrm{NMR}$ spectrum of compound 4 (in $\mathrm{CD}_{3} \mathrm{OD}$ ), Figure S9: LC/MS data (detection wavelength was set as $210 \mathrm{~nm}$ ) of compound 4, Figure S10: ${ }^{1} \mathrm{H}-\mathrm{NMR}$ spectrum of compound 5 (in $\mathrm{CDCl}_{3}$ ), Figure S11: ${ }^{13} \mathrm{C}-\mathrm{NMR}$ spectrum of compound 5 (in $\mathrm{CDCl}_{3}$ ), Figure S12: LC/MS data (detection wavelength was set as $210 \mathrm{~nm}$ ) of compound 5.

Author Contributions: Conceptualization, S.A.Y., T.S.J. and K.H.K.; Formal analysis, H.K., M.J.Y., S.A.Y., T.W.K., J.-W.H., M.W.N., K.H.P., S.-H.K. and J.W.H.; Investigation, H.K., M.J.Y., S.A.Y. and K.H.P.; Writing—original draft preparation, H.K., M.J.Y. and K.H.K.; Writing-review and editing, S.A.Y. and K.H.K.; Visualization, H.K. and M.J.Y.; Supervision, T.S.J. and K.H.K.; Project administration, K.H.K.; Funding acquisition, K.H.K. All authors have read and agreed to the published version of the manuscript.

Funding: This work was supported by a grant from the National Research Foundation of Korea (NRF), funded by the Korean government (MSIT) (grant number: 2019R1A5A2027340 and 2021R1A2C2007937). This work was also supported by the Nano Convergence Industrial Strategic Technology Development Program (20000105, Development of Cosmeceutical Material Platform using Organo-Nano Complexes based on Natural Active Compounds) funded by the Ministry of Trade, Industry \& Energy (MOTIE, Korea).

Institutional Review Board Statement: Not applicable.

Informed Consent Statement: Not applicable.

Conflicts of Interest: The authors declare no conflict of interest.

\section{References}

1. Spiegelman, B.M.; Flier, J.S. Obesity and the regulation of energy balance. Cell 2001, 104, 531-543. [CrossRef]

2. Smith, U.; Kahn, B.B. Adipose tissue regulates insulin sensitivity: Role of adipogenesis, de novo lipogenesis and novel lipids. J. Intern. Med. 2016, 280, 465-475. [CrossRef] [PubMed]

3. Kim, M.S.; Sharma, B.R.; Rhyu, D.Y. Beneficial effect of Lespedeza cuneata (G. Don) water extract on streptozotocin-induced type 1 diabetes and cytokine-induced beta-cell damage. Nat. Prod. Sci. 2016, 22, 175-179. [CrossRef]

4. Zhang, C.; Zhou, J.; Yang, J.; Li, C.; Ma, J.; Zhang, D.; Zhang, D. Two new phenylpropanoid glycosides from the aerial parts of Lespedeza cuneata. Acta Pharm. Sin. B 2016, 6, 564-567. [CrossRef] [PubMed]

5. Min, J.Y.; Shim, S.H. Chemical constituents from Lespedeza cuneata G. Don (leguminosae). Biochem. Syst. Ecol. 2016, 66, 293-296. [CrossRef]

6. Kim, S.M.; Kang, K.; Jho, E.H.; Jung, Y.J.; Nho, C.W.; Um, B.H.; Pan, C.H. Hepatoprotective effect of flavonoid glycosides from Lespedeza cuneata against oxidative stress induced by tert-butyl hyperoxide. Phytother. Res. 2011, 25, 1011-1017. [CrossRef]

7. Zhang, C.F.; Zhou, J.; Yang, J.Z.; Li, C.J.; Ma, J.; Zhang, D.; Li, L.; Zhang, D.M. Three new lignanosides from the aerial parts of Lespedeza cuneata. J. Asian Nat. Prod. Res. 2016, 18, 913-920. [CrossRef]

8. Park, B.K.; Kim, C.W.; Kwon, J.E.; Negi, M.; Koo, Y.T.; Lee, S.H.; Baek, D.H.; Noh, Y.H.; Kang, S.C. Effects of Lespedeza cuneata aqueous extract on testosterone-induced prostatic hyperplasia. Pharm. Biol. 2019, 57, 89-97. [CrossRef]

9. $\quad$ Park, B.; Kwon, J.E.; Cho, S.M.; Kim, C.W.; Koo, Y.T.; Lee, S.H.; Lee, H.M.; Kang, S.C. Protective effect of Lespedeza cuneata ethanol extract on bisphenol a-induced testicular dysfunction in vivo and in vitro. Biomed. Pharmacother 2018, 102, 76-85. [CrossRef]

10. Matsuura, S.; Iinuma, M.; Ito, E.; Takami, H.; Kagei, K. Studies on the constituents of the useful plants. Viii. The constituents of Lespedeza cuneata G. Don (author's transl). Yakugaku Zasshi 1978, 98, 1542-1544. [CrossRef]

11. Yoo, G.; Park, S.J.; Lee, T.H.; Yang, H.; Baek, Y.S.; Kim, N.; Kim, Y.J.; Kim, S.H. Flavonoids isolated from Lespedeza cuneata G. Don and their inhibitory effects on nitric oxide production in lipopolysaccharide-stimulated BV-2 microglia cells. Pharmacogn. Mag. 2015, 11, 651. [PubMed]

12. Zhou, J.; Li, C.J.; Yang, J.Z.; Ma, J.; Wu, L.Q.; Wang, W.J.; Zhang, D.M. Phenylpropanoid and lignan glycosides from the aerial parts of Lespedeza cuneata. Phytochemistry 2016, 121, 58-64. [CrossRef] [PubMed]

13. Lee, S.R.; Kang, H.S.; Yoo, M.J.; Yi, S.A.; Beemelmanns, C.; Lee, J.C.; Kim, K.H. Anti-adipogenic Pregnane Steroid from a Hydractinia-associated Fungus, Cladosporium sphaerospermum SW67. Nat. Prod. Sci. 2020, 26, 230-235.

14. Lee, S.; Ryoo, R.; Choi, J.H.; Kim, J.H.; Kim, S.H.; Kim, K.H. Trichothecene and tremulane sesquiterpenes from a hallucinogenic mushroom Gymnopilus junonius and their cytotoxicity. Arch. Pharm. Res. 2020, 43, 214-223. [CrossRef] [PubMed]

15. Trinh, T.A.; Park, E.J.; Lee, D.; Song, J.H.; Lee, H.L.; Kim, K.H.; Kim, Y.; Jung, K.; Kang, K.S.; Yoo, J.E. Estrogenic activity of sanguiin H-6 through activation of estrogen receptor $\alpha$ coactivator-binding site. Nat. Prod. Sci. 2019, 25, 28-33. [CrossRef]

16. Ha, J.W.; Kim, J.; Kim, H.; Jang, W.; Kim, K.H. Mushrooms: An Important Source of Natural Bioactive Compounds. Nat. Prod. Sci. 2020, 26, 118-131. 
17. Baek, J.; Lee, D.; Lee, T.K.; Song, J.H.; Lee, J.S.; Lee, S.; Yoo, S.W.; Kang, K.S.; Moon, E.; Lee, S.; et al. (-)-9'-O-( $\alpha-L-$ rhamnopyranosyl) lyoniresinol from Lespedeza cuneata suppresses ovarian cancer cell proliferation through induction of apoptosis. Bioorg. Med. Chem. Lett. 2018, 28, 122-128. [CrossRef]

18. Baek, J.; Lee, T.K.; Song, J.H.; Choi, E.; Ko, H.J.; Lee, S.; Choi, S.U.; Lee, S.; Yoo, S.W.; Kim, S.H.; et al. Lignan glycosides and flavonoid glycosides from the aerial portion of Lespedeza cuneata and their biological evaluations. Molecules 2018, $23,1920$. [CrossRef]

19. Lee, D.; Lee, Y.H.; Lee, K.H.; Lee, B.S.; Alishir, A.; Ko, Y.J.; Kang, K.S.; Kim, K.H. Aviculin isolated from Lespedeza cuneata induce apoptosis in breast cancer cells through mitochondria-mediated caspase activation pathway. Molecules 2020, 25, 1708. [CrossRef]

20. Chen, C.R.; Chao, L.H.; Liao, Y.W.; Chang, C.I.; Pan, M.H. Tocopherols and triterpenoids from Sida acuta. J. Chin. Chem. Soc. 2007, 54, 41-45. [CrossRef]

21. Waridel, P.; Wolfender, J.L.; Lachavanne, J.B.; Hostettmann, K. Ent-labdane glycosides from the aquatic plant Potamogeton lucens and analytical evaluation of the lipophilic extract constituents of various potamogeton species. Phytochemistry 2004, 65, 945-954. [CrossRef]

22. Naidu, S.V.; Gupta, P.; Kumar, P. Enantioselective syntheses of (-)-pinellic acid, $\alpha$-and $\beta$-dimorphecolic acid. Tetrahedron 2007, 63, 7624-7633. [CrossRef]

23. Fotie, J.; Bohle, D.S.; Leimanis, M.L.; Georges, E.; Rukunga, G.; Nkengfack, A.E. Lupeol long-chain fatty acid esters with antimalarial activity from Holarrhena floribunda. J. Nat. Prod. 2006, 69, 62-67. [CrossRef]

24. Walther, T.C.; Farese, R.V., Jr. Lipid droplets and cellular lipid metabolism. Annu. Rev. Biochem. 2012, 81, 687-714. [CrossRef]

25. Marcelin, G.; Chua, S., Jr. Contributions of adipocyte lipid metabolism to body fat content and implications for the treatment of obesity. Curr. Opin. Pharmacol. 2010, 10, 588-593. [CrossRef] [PubMed]

26. Lee, S.R.; Yi, S.A.; Nam, K.H.; Ryoo, R.; Lee, J.; Kim, K.H. Pantheric acids A-C from a poisonous mushroom, Amanita pantherina, promote lipid accumulation in adipocytes. J. Nat. Prod. 2019, 82, 3489-3493. [CrossRef] [PubMed]

27. Yi, S.A.; Lee, J.; Park, S.K.; Kim, J.Y.; Park, J.W.; Lee, M.G.; Nam, K.H.; Park, J.H.; Oh, H.; Kim, S.; et al. Fermented ginseng extract, BST204, disturbs adipogenesis of mesenchymal stem cells through inhibition of S6 kinase 1 signaling. J. Ginseng Res. 2020, 44, 58-66. [CrossRef] [PubMed]

28. Olzmann, J.A.; Carvalho, P. Dynamics and functions of lipid droplets. Nat. Rev. Mol. Cell Biol. 2019, 20, 137-155. [CrossRef] [PubMed]

29. Kokta, T.; Strat, A.; Papasani, M.; Szasz, J.; Dodson, M.; Hill, R. Regulation of lipid accumulation in 3t3-11 cells: Insulinindependent and combined effects of fatty acids and insulin. Animal 2008, 2, 92-99. [CrossRef] [PubMed]

30. Guo, Y.; Walther, T.C.; Rao, M.; Stuurman, N.; Goshima, G.; Terayama, K.; Wong, J.S.; Vale, R.D.; Walter, P.; Farese, R.V. Functional genomic screen reveals genes involved in lipid-droplet formation and utilization. Nature 2008, 453, 657-661. [CrossRef] [PubMed] 